\title{
BAETICA, 40 AÑOS DE HISTORIA CONTEMPORÁNEA. INVESTIGACIONES, TENDENCIAS Y NUEVOS RETOS
}

\author{
Sergio Blanco Fajardo* \\ UniversidAd de MÁlaga
}

\section{RESUMEN}

En el presente artículo se aborda la trayectoria de la revista Baetica a lo largo de sus cuarenta años de existencia. En concreto, nos centraremos en la producción encuadrada en la etapa contemporánea. El objetivo es realizar un análisis a través del grueso de sus publicaciones para definir unas tendencias historiográficas marcadas por la historia local sin abandonar temáticas de estudio con enfoques más amplios. Este largo recorrido nos situará en la línea de las investigaciones que han ido irrumpiendo en el panorama nacional y se han reflejado en la revista malacitana. En último lugar, realizaremos un balance global del pasado y presente de la revista arrojando pinceladas sobre posibles ejes temáticos de futuro.

PALABRAS CLAVE: revista Baetica, historiografía, Universidad de Málaga, Historia Contemporánea, historial local 


\title{
BAETICA, FORTY YEARS OF CONTEMPORANEAN HISTORY. RESEARCH, TENDENCIES AND NEW CHALLENGES
}

\author{
Sergio Blanco Fajardo* \\ Malaga UNIVERSITY
}

\begin{abstract}
This article addresses the development of Baetica's journal throughout its forty years of existence. Specifically, we will focus on the production framed in the contemporary stage. The objective is to carry out an analysis through the thick of its publications to define historiographic tendencies marked by local history without neglect study themes with broader approaches. This long journey will place us in the line of the researchs that have been breaking into the national scene and have been reflected in the journal. Finally, we will make a global balance throwing possible thematic axes of the future.
\end{abstract}

KEYWORDS: Baetica journal, historiography, Malaga University, Contemporanean history, local history

Enviado: 18-12-2019

Aceptado: 28-1-2020

*sbf@uma.es 


\section{BAETICA: EL TRASUNTO DE UNA NUEVA GENERACIÓN}

Hace cuarenta años veía la luz el primer número de la revista Baetica editada en la Facultad de Filosofía y Letras de la Universidad de Málaga ${ }^{1}$. Surgía tan solo cuatro años después de la inauguración de la facultad que impulsó su creación, al calor de la primera promoción de estudiantes y, paralelamente, como manifestación de las inquietudes intelectuales del profesorado de las ramas de Historia, Arte y Geografía. El afán del conocimiento y la investigación se enmarcaba en una etapa de transición política, de efervescencia social y cultural que se manifestó dentro de las propias universidades y en su movimiento estudiantil.

El nuevo sistema político, la democracia, significó la apertura hacia una historia de España repensada años atrás por historiadores como Manuel Tuñón de Lara, Javier Tusell o José María Jover ${ }^{2}$ bajo el influjo de la Escuela de Annales y la escuela marxista inglesa, entre otros, una actividad que dio paso paulatinamente a la renovación de la Historia Política y la Historia Social y al cambio de paradigma de lo macro a lo micro que se promovió en Europa en los años 70 del siglo pasado ${ }^{3}$. En esta tesitura, recogidas estas influencias epistemológicas, las universidades españolas sufrieron una renovación que cambió la forma de entender la disciplina y la producción del relato histórico. La dinamización provocada por las nuevas tendencias historiográficas acusó su efecto en los diversos departamentos contemporaneístas de nuestro suelo que, al igual que en el caso malacitano, crearon revistas científicas ${ }^{4}$ procurando nuevos enfoques a la investigación histórica.

La práctica de la historia local en España experimentó en el año 1976 sus cotas más altas alcanzando un porcentaje del $20 \%$ del total de la pro-

1. Este trabajo ha sido posible gracias a la ayuda para la Formación del Profesorado Universitario (FPU) otorgada por el Ministerio de Educación de España. FPU16/00874.

2. J. M. Jover Zamora (1976); M. TuÑón de Lara (1978a); (1978b); J. Tusell (1975); (1977).

3. E. Hernández Sandoica (2004), 15-16.

4. Entre las revistas que se sujetan en el mismo eje cronológico que Baetica (1978) encontramos a Anuario de Historia Contemporánea (1974) en la Universidad de Granada, Cuadernos de Historia Moderna y Contemporánea (1980) en la Universidad Complutense de Madrid, Anales de Historia Contemporánea (1982) en la Universidad de Murcia, Anales de la Universidad de Alicante (1982), Revista de Historia Contemporánea (1982) en la Universidad de Sevilla y Studia Histórica. Historia Contemporánea (1983) en la Universidad de Salamanca. 
ducción científica anual ${ }^{5}$. La tendencia que caracterizaba la historiografía española se manifestó, en buena medida, en las publicaciones citadas anteriormente que alentaron el estudio histórico a nivel provincial, con el objetivo de iluminar determinados contextos de menor entidad territorial. El regionalismo había pasado de soslayo por la historia, recayendo el interés en los denominados eruditos locales que se esforzaron en plasmar textualmente los acontecimientos pretéritos acontecidos en sus núcleos vivenciales, relegando a su esfera de actuación el "oficio profesional" de la historia. Sin embargo, durante la primera mitad del siglo XX, los historiadores iniciaron un pulso para recuperar la potestad del discurso histórico desterrando los tintes descriptivos que caracterizaban este tipo de relatos.

La renovación metodológica, documental y epistemológica producida a partir de la segunda mitad del siglo XX, sobre todo hacia 1970, galvanizó la historia local refinando sus presupuestos y objetivos ${ }^{6}$. Del acento puesto en el dato y en lo "anecdótico" se pasó a un modo de hacer historia en el que los individuos y los colectivos estuviesen relacionados con las estructuras, la dimensión política y los procesos sociales ${ }^{7}$. No obstante, el cambio de paradigma propuesto, después, por la microhistoria ofrecería una visión de abajo a arriba, es decir, se inclinaría a descubrir cómo participa lo local en lo general, conformando una nueva metodología en la coyuntura política que atravesaba España: por un lado surgió el Estado de las autonomías, hecho que conllevaría un creciente interés por la historia regional, del que son una prueba las investigaciones de Fernando Arcas y Juan Antonio Lacomba sobre el andalucismo histórico ${ }^{8}$, y por otro, la cercanía de los archivos locales y la desclasificación o liberación de fuentes hasta entonces no estudiadas facilitaría la construcción de esos registros históricos. En este marco se produce el nacimiento de Baetica, que, como hija de su tiempo, se comprometió en la empresa de difundir tanto los nuevos caminos de la historia como los de otras disciplinas ubicadas en el campo de las humanidades.

\section{TENDENCIAS, DEBATES Y FUENTES DOCUMENTALES}

Dado su carácter multidisciplinar, en su primera etapa (1978-2015), la estructura de la revista presentaba un bloque ordenado por áreas de

5. M. Marín Gelabert (2001), 138.

6. J. A. Lacomba Abellán (1995), 129.

7. J. Serna y A. Pons (1993), 131.

8. F. Arcas Cubero (1980); J.A. Lacomba Abellán (2008). 
conocimiento según una división cronológica por etapas históricas. Circunscribiéndonos a las publicaciones realizadas en el ámbito de la Historia Contemporánea, en el primer número publicado en 1978 Antonio Nadal Sánchez abordaba, en un trabajo sobre las fuentes bibliográficas y documentales de la guerra civil en Málaga, una temática que iba a suscitar gran interés historiográfico ${ }^{9}$.

El conflicto bélico ha sido quizá el acontecimiento que mayor volumen de estudios y debates ha promovido en el territorio nacional ${ }^{10}$, incluyendo en ellos los relatos legitimadores escritos desde la perspectiva de los ganadores $\mathrm{y}$, en otra vertiente, las respuestas críticas construidas desde el exilio. Restablecida la democracia, los primeros estudios estuvieron influenciados por las investigaciones acometidas por los hispanistas ${ }^{11}$, un capítulo en el cual destacó el modelo interpretativo anglosajón. Al calor de estas propuestas, los trabajos de los investigadores españoles no se hicieron esperar. Desde los últimos años de la década de los 70 se consolidaron las contribuciones que aportaban nuevos análisis y perspectivas, destacando las interpretaciones de Manuel Tuñón de Lara, Julio Aróstegui, Ángel Viñas Mey o Gabriel Cardona ${ }^{12}$.

El cincuenta aniversario de la guerra civil, del mismo modo que las revisiones llevadas a cabo en las dos décadas siguientes, fue aprovechado por autores y editoriales para difundir, a título novedoso, hilos argumentales que se habían considerado hasta ese momento "delicados"13. Este hecho no comportaba que las investigaciones hubieran decaído, al contrario, dibujaron una línea de trabajo constante que se vio reforzada gracias a las aportaciones dedicadas a la etapa republicana ${ }^{14}$ y 1 los primeros años del franquismo ${ }^{15}$. Fruto de ese interés fue el artículo que Encarnación Barranquero dedicó a la implantación en 1937 del Nuevo Estado en el Ayuntamiento malacitano, asegurando en sus páginas que el

\section{A. Nadal SÁnchez (1978).}

10. J. Aróstegui (coord.) (1988), 11.

11. R. Fraser (1979); R. Carr (1977); S. Payne (1976); P. Preston (2011), se trata de una versión actualizada, en el texto nos referimos a la obra publicada en 1978; H. Тномаs (1977); H. Raguer (1977); P. Broué y E. Témime (1977); G. Jackson (1976).

12. A. Viñas Mey (1979); M. Tuñón de Lara, J. Aróstegui, Á. Viñas Mey, G. Cardona y J. M. Bricall (1985); J. Aróstegui (1985).

13. J.A. Blanco Rodríguez (2007), 23.

14. J. Santos (1984); J. J. Carreras Ares (1981); J. Tusell (1982); M. Tuñón de Lara (1985); M. Nash (1981); R. M. ${ }^{a}$ Capel Martínez (1975a).

15. J. Fontana (1986); M. ${ }^{a}$ T. Gallego Méndez (1983); F. Romeu Alfaro (1987); Á. Viñas Mey (1984); M. Espadas Burgos (1987); M. J. González (1979); J. C. Losada Álvarez (1990); J. M. a Maravall (1978); A. Alted Vigil (1991). 
gobierno local fue un fiel reflejo del poder establecido por Franco y sus seguidores ${ }^{16}$. Por su parte, José Velasco Gómez, centrado en el periodo inmediatamente anterior, abordó las elecciones de 1936 en la provincia de Málaga, que dieron paso al gobierno frentepopulista, un episodio no exento de polémicas historiográficas y políticas ${ }^{17}$. Pero no fue esta la única coyuntura electoral analizada en la etapa republicana, como refleja María Dolores Ramos Palomo en su artículo sobre el sufragio femenino y las elecciones de $1933^{18}$. Este y otros acontecimientos tuvieron a las mujeres como protagonistas en los años treinta.

En la década de los 90, las investigaciones sobre la guerra civil y el franquismo acentuaron el ámbito local ${ }^{19}$, respondiendo a la facilidad del acceso a las fuentes y, en gran medida, el interés por las cuestiones específicas que arrojaban lo local o regional insertas en coyunturas históricas generale ${ }^{20}$. Esta etapa condensa una línea permanente en las publicaciones de Baetica cristalizada en los trabajos de Antonio Nadal Sánchez ${ }^{21}$ y Encarnación Barranquero Texeira ${ }^{22}$, aunque pronto le siguieron los estudios de Lucía Prieto Borrego y Cristian Cerón Torreblanca. Por su parte, María Dolores Ramos Palomo realizó una contribución enmarcada en la experiencia de los exiliados relatando "el lenguaje de los perdedores", es decir, la producción literaria realizada como trasunto de la memoria de la guerra y la construcción identitaria y subjetiva del exilio español ${ }^{23}$.

Con el cambio de milenio se introducirá una mayor diversidad en la producción científica acercando la lente hacia aspectos que habían pasado de soslayo $^{24}$ y recurriendo al uso de la historia oral ${ }^{25}$ en una inclinación hacia el estudio de lo subjetivo que implicaría la construcción de nuevos discursos, o al menos, la necesidad de relativizar y matizar el relato históri-

16. E. Barranquero Texeira (1988).

17. J. Velasco Gómez (1983).

18. M. ${ }^{\text {a }}$ D. Ramos Palomo (1988).

19. J. Casanova (1999); I. Blasco Herranz (1999); Á. Cenarro (1995).

20. J. Aróstegui (1992), 89-90.

21. A. Nadal Sánchez (1983); (2006).

22. E. Barranquero Texeira (1998).

23. M. ${ }^{a}$ D. Ramos Palomo (1998).

24. E. Moradiellos (2001); J. Sobrequés i Callico, C. Molinero y M. Sala (2003); M. NúÑez Díaz-Balart (2006); Á. Viñas Mey (2006); M. ${ }^{a}$ C. Muñoz Ruiz (2002); E. Silva y S. Macías (2003); M. Á. Del Arco Blanco (2007); M. Nash (2006), M. Moreno SECO (2012).

25. J. Aróstegui (1992), pp. 89-90. 
$\mathrm{co}^{26}$. De este modo, los artículos firmados por Lucía Prieto encajan en esta coyuntura historiográfica introduciendo temáticas novedosas. En su trabajo sobre la Causa General de Casares, describe la represión experimentada por sus habitantes, tanto por parte de la república como del ejército franquista, y el cambio drástico que supuso en la intrahistoria de este pequeño pueblo que mira hacia Gibraltar ${ }^{27}$. En la línea de los estudios sobre la represión, el poder y las violencias en el ámbito local, se emplazan sus aportaciones de la violencia anticlerical en las comarcas de Marbella y Ronda durante la guerra civil $^{28}$ y la justicia popular desplegada en Istán y Estepona ${ }^{29}$. Posteriormente, Cristian Cerón ${ }^{30}$ publicaría una investigación sobre Falange en Málaga y su evolución política durante los años del primer franquismo, ocupándose también, en contraposición, de la puesta en escena de la oligarquía local que el propio régimen sustentó y que supuso un pulso por conseguir espacios de poder y menoscabar la influencia del partido único. Sin abandonar la veta de la represión franquista Manuel Morales diserta en otro artículo sobre la naturaleza, la tipología y el impacto de la represión franquista en Málaga ${ }^{31}$.

El hecho de que desde ciertos sectores se retomaran mitos históricos que habían sido construidos por el franquismo con el respaldo de la censura durante cuarenta años ${ }^{32}$, fue contestado por numerosos historiadores ${ }^{33}$. En esta línea, Cristian Cerón se sumaba en el marco del 70 aniversario de la Guerra Civil a la iniciativa de replicar a quienes que pretendían transformar la interpretación y la difusión del relato histórico en un burdo instrumento político $^{34}$.

Si nos adentramos ahora en otros ámbitos historiográficos, comprobaremos que la New Economic history vino a renovar en los años 50 del pasado siglo la concepción de la disciplina y la metodología que los historiadores de la economía inscribían en sus trabajos. El fenómeno, que tuvo su epicentro

26. P. Aguilar (2008); E. Barranquero Texeira y L. Prieto Borrego (2003); P. Domínguez (1994); S. Rodríguez López (2008); M. Llona (2002); P. SÁnchez (2009); E. de Dios FERNÁNDEZ (2016).

27. L. Prieto Borrego (2000).

28. L. Prieto Borrego (2003).

29. L. Prieto Borrego (2004).

30. C. Cerón Torreblanca (2008).

31. M. Morales MuÑoz (2008).

32. E. Moradiellos (2007).

33. F. Espinosa Mestre (2005); A. Reig Tapia (2006); J. Casanova (2008).

34. C. Cerón Torreblanca (2007). 
en la escuela norteamericana ${ }^{35}$, no prescribió en su ambición reformadora, al contrario, la cliometría, la cuantificación y el deductivismo positivista siguieron inundando su praxis científica. La virtud de este cambio teórico y práctico radicó en la amplitud de sus perspectivas, entre las que cabe destacar la posibilidad de introducir lo social y cultural en el método de análisis, una actividad científica que encuentra su precedente en los análisis de Weber y Durkheim. Este hecho fue el punto de partida de una posterior reflexión sobre la historia económica de la mano de autores insertos en diferentes líneas o escuelas, una de ellas la antropología económica de Karl Polanyi ${ }^{36}$, y otra la que postula la relación social y cultural reflejada por Carlo M. Cipolla ${ }^{37}$, resultando una evolución compleja y diversificada, fruto de la interdisciplinariedad y los préstamos recogidos por la sociología y la antropología ${ }^{38}$.

Estas relaciones entre economía y sociedad son palpables en los trabajos de María Dolores Ramos sobre la estructura social, los grupos de presión y el somaten en Málaga en el periodo 1914-1923 ${ }^{39}$, y los de Manuel Morales sobre las élites y su papel en la industrialización andaluza ${ }^{40}$. Este autor y Emilio Ortega Berenguer dilucidan las redes existentes entre el poder político y el económico a través del asociacionismo empresarial andaluz de entre siglos ${ }^{41}$. Por otra parte, el impacto del desarrollo tecnológico y el maquinismo en la Málaga de la segunda mitad del siglo XIX es descrito por Cristóbal García Montoro ${ }^{42}$, que, siguiendo con la misma temática, firma un segundo artículo sobre el proteccionismo desarrollado por los industriales malagueños en la centuria decimonónica ${ }^{43}$.

Sin duda estos planteamientos se enmarcan, como apuntábamos anteriormente, en los cambios que la historiografía global estaba experimentando en los años 70 y 80 y en las formas de aplicar, los estudios económicos en las diversas coyunturas históricas. Fruto de esta diversificación son el trabajo de María José González Castillejo sobre la instrumentalización

35. D. C. North (1971); R. Fogel (1994).

36. K. Polanyi (2018).

37. C. M. Cipolla (1991).

38. E. Hernández Sandoica (2004), 151-203.

39. M. ${ }^{a}$ D. Ramos palomo (1985), (1986), (1987).

40. M. Morales MuÑoz (1999).

41. M. Morales Muñoz y E. Ortega Berenguer (2001).

42. C. García Montoro (1978).

43. C. García Montoro (1979). 
económica de la publicidad como herramienta de la lucha de clases $^{44}$ y la investigación de María Dolores Ramos en torno al I Plan de Desarrollo Económico orquestado por el gobierno franquista en 1964 y su repercusión en el proyecto de industrialización de la ciudad malacitana ${ }^{45}$.

Por otra parte, las tendencias referidas a la historia económica y social han derivado, al calor de la diversidad metodológica y del interés de numerosas investigaciones, en especialidades de enorme interés. Una de ellas, quizá la más relevante, es la historia de la empresa (Business history) ${ }^{46}$. En este ámbito, la línea de investigación de Mercedes Fernández Paradas sobre la historia de la electricidad y del gas en España, ocupa un lugar en la revista con la publicación de dos artículos: el primero sobre los comienzos de la electricidad en Andalucía ${ }^{47}$ y, el segundo sobre la casa Carreira, ejemplo de una pequeña empresa eléctrica en la región.

\subsection{La nueva historia política y la historia sociocultural}

Las bases de lo que hoy podemos definir como historia social las encontramos en dos corrientes principales a las que nos hemos referido anteriormente: la Escuela de Anales y el marxismo histórico británico. A pesar de las diferencias metodológicas, basadas en la historia marxista en una concepción dual, infraestructura y superestructura, y en el caso de los analistas, en diversos niveles o temporalidades, lo cierto es que ambas corrientes postulan la importancia de las condiciones sociales de existencia frente a la historia anterior que tendía a disociar lo institucional y el ámbito de las ideas, y desatendía las relaciones del individuo con la estructura social ${ }^{48}$.

No obstante, el herraje metodológico de la historia social quedaría incompleto sin plasmar el giro subjetivo que supuso la microhistoria y también las relevantes influencias de la antropología, la psicología social y la sociología, posibilitando así una nueva forma de aproximarse a la historia y a sus fuentes. La complejidad y la diversidad del análisis histórico en la década de los 70 y 80 del pasado siglo, implicaron en buena medida, el interés por numerosos temas.

44. M. ${ }^{a}$ J. González Castillejo (1999).

45. M. ${ }^{a}$ D. Ramos Palomo (1994).

46. E. Hernández Sandoica (2004), 226-227.

47. M. Fernández Paradas (2010).

48. M. Á. Cabrera Acosta (2001), 256. 
Los nuevos enfoques conceptuales y metodológicos legitimaron la construcción de la historia de la vida cotidiana, la historia de las sensibilidades y la historia de la cultura popular, que tuvieron su precedente en la historia de las mentalidades propuesta por Annales durante la segunda mitad del siglo XX. Debemos entender su aparición como fruto de la evolución y diversificación de la historia social que avanzaba en sus modelos y supuestos teóricos y metodológicos a un ritmo inusitado ${ }^{49}$.

Por otra parte, a mediados de los años 80 surgió un replanteamiento de la historia social producido por su aproximación hacia lo cultural y el posterior giro lingüístico ${ }^{50}$. Pero en buena medida, el trasvase de un enfoque a otro no iba a comportar un movimiento rupturista o un cambio radical. La historia cultural continuaría utilizando fuentes análogas a las que usaba la historia social. La diferencia radica en los enfoques, que en los relatos de historia cultural se dirigen a las representaciones, las experiencias, las percepciones, es decir, subrayan la interrelación simbólica establecida entre los sujetos históricos y las manifestaciones culturales.

La acogida en España de los cambios historiográficos acontecidos en Europa también propició la reconceptualización de lo político al hilo de modelos y métodos analíticos diferentes. Estos enfoques abogaban por un dialogo entre lo cultural y lo social derivando en una visión poliédrica de lo político. Fue Tuñón de Lara, durante el Coloquio de Pau celebrado el 20 y 21 marzo de $1970^{51}$, quien se centró en las organizaciones obreras, uno de los primeros signos de la innovación historiográfica que se aproximaba. Cristóbal García Montoro ${ }^{52}$ se haría eco de la nueva veta abierta por el historiador matritense y en 1980 publicó un artículo sobre el ludismo en Antequera a mediados del siglo XIX. Es sintomática la alusión a los Coloquios de Pau, que sirvieron de acicate al estudio del movimiento obrero entre los historiadores contemporaneístas.

Por su parte, el Área de Historia Contemporánea de la Universidad de Málaga reflejó su interés por el estudio de la conflictividad social y el movimiento obrero. En consecuencia, María Dolores Ramos haría énfasis en la Gran Guerra ${ }^{53}$, un periodo caracterizado por la conflictividad social y que lejos de mostrar un carácter pacífico en relación con la neutralidad

49. E. Hernández Sandoica (2005), 7-8.

50. G. Eley (2008), 271-278; M. ${ }^{a}$ D. Ramos Palomo (1993).

51. M. Tuñón de LARA (1980).

52. C. García Montoro (1980).

53. M. ${ }^{\text {a }}$ D. Ramos Palomo (1980). 
oficial española fue marco de numerosas agitaciones materializadas, entre otros episodios, en la huelga de los Altos Hornos en Málaga y los conflictos de subsistencias desarrollados en enero de $1918^{54}$. En esta misma línea José Antonio Parejo Barranco analiza una crisis similar provocada por el precio y la carestía de los cereales en Antequera poco antes del Sexenio revolucionario $^{55}$, y José Velasco traslada su objeto de estudio a la órbita rural relatando la conflictividad campesina en Antequera durante el bienio azañista ${ }^{56}$. También Manuel Morales se especializó en el estudio de los movimientos sociales, en especial durante el siglo XIX, abordando en un artículo la conflictividad experimentada en Málaga durante el Sexenio revolucionario ${ }^{57}$.

Es cierto que, desde otra instancia, las inquietudes intelectuales se extendieron al campo de las culturas políticas, en relación la diversificación metodológica desarrollada en la historiografía española durante la década de los 80, razón por la que Manuel Morales ahonda en las bases sociológicas malacitanas durante el sistema político del Sexenio ${ }^{58}$, en el papel desarrollado por el sector anarquista en la huelga general de $1872^{59}$ y en la introducción de la Federación Regional Española de la AIT en el campesinado malagueño ${ }^{60}$. Por su parte, Fernando Arcas ${ }^{61}$ se ocupa en otras dos contribuciones de las consecuencias sociales de la guerra del 98 y de la trayectoria de Unión Republicana a comienzos del siglo XX en Málaga.

En el ámbito de entrecruzamientos entre lo social, lo político y lo cultural encontramos otros ejes temáticos que tuvieron resonancia durante estos años. En esta dinámica Emilio Ortega Berenguer centró su investigación en los aspectos educativos y la enseñanza, publicando sus trabajos en torno a la educación en Málaga antes de la implantación de la Segunda República $^{62}$ o sobre la enseñanza desde la mitad del siglo XIX hasta la reforma de $\mathrm{Madoz}^{63}$.

Por otra parte, a tono con el interés de la asignatura Historia del Movimiento Obrero, ofertada por el área de Historia Contemporánea du-

54. M. ${ }^{\text {a }}$ D. Ramos Palomo (1983).

55. J. A. Parejo Barranco (1980).

56. J. Velasco Gómez (1982).

57. M. Morales Muñoz (1982).

58. M. Morales MuÑoz (1983).

59. M. Morales MuÑoz (1992).

60. M. Morales Muñoz (1991).

61. F. Arcas Cubero (1989), (1982).

62. E. Ortega Berenguer (1978).

63. E. Ortega Berenguer (1985). 
rante veinte años, no es de extrañar que la producción relacionada con esta materia tuviese en la década de los 90 y en el nuevo milenio una continuidad respaldada por la amplitud de conocimientos y el uso de nuevas fuentes, si bien, es cierto, con un enfoque renovado. Encontramos testimonios de ello en el artículo de Encarnación Barranquero sobre la conflictividad laboral del sector textil durante el segundo franquismo ${ }^{64}$, un tema que también aborda Cristian Cerón acercando al público lector a la prevención de los riesgos laborales en la dictadura ${ }^{65}$. Interesante es la perspectiva que se recoge en los artículos de Carmen Romo Parra, que reflexiona sobre conceptos como el trabajo, el tiempo y la sociedad de consumo dejando entrever las ramificaciones y avances de una historia sociocultural que se imbrica con lo económico y lo político ${ }^{66}$. En fin, no podemos abandonar este ámbito sin mencionar la aportación de Lucía Prieto sobre las condiciones de vida de la clase obrera de la localidad de Marbella a principios del siglo $\mathrm{XX}^{67}$.

Desde la década de 1990 se vienen produciendo una serie de debates historiográficos centrados en la complejidad que arrojan las investigaciones en el terreno de lo social ${ }^{68}$. En esta tesitura, más allá de las propuestas del giro lingüístico, se consolida la historia sociocultural, que asimila el concepto de representación para explicar de qué manera los referentes culturales actúan en la sociedad ${ }^{69}$. Según apunta María Dolores Ramos, "las «representaciones» incluirían tanto las formas en que los sujetos históricos interiorizan su percepción y clasificación en el mundo como las «prácticas» con las que los individuos intentan mostrar un determinado estatus o identidad social"70. En esta interpretación los sujetos pierden cualquier carácter pasivo y se reapropian de discursos y esquemas culturales otorgándoles significados diferentes en función de la clase social, el sexo, la cultura política, la etnia o la edad, y dando lugar a un sistema de negociaciones en el que pueden operar o no, paralelamente, las experiencias y los conceptos asimilados anteriormente. De esta forma, la historia cultural y la historia sociocultural rechazan la concepción parcial o sesgada de lo social expuesta en categorías dicotómicas como son los términos "cultura

64. E. Barranquero Texeira (1997).

65. C. Cerón Torreblanca (2010).

66. C. Romo Parra (1996); (2005).

67. L. Prieto Borrego (2001).

68. J. Arostegui (1995); J. Casanova (1992); M. ${ }^{a}$ D. Ramos Palomo (1993).

69. R. Chartier (1994); G. M. Spiegel (2006).

70. A. Aguado y M. ${ }^{\mathrm{a}}$ D. Ramos Palomo (2002). 
popular" y cultura burguesa", términos que la historia actual ha replanteado eliminando su carácter reduccionista ${ }^{71}$.

Esta nutrida y compleja red conceptual y metodológica fue paulatinamente asumida por la historiografía española. En este sentido, vislumbramos el ejercicio teórico de María Dolores Ramos que aúna en su estudio sobre familismo y economía campesina las categorías de clase, de género y generacional en el tratamiento de los sujetos históricos que se contraponen a las pautas hegemónicas ${ }^{72}$. El artículo de Lucía Prieto, en el que aborda la prostitución en Andalucía durante el primer franquismo, delata el interés por un eje temático que diverge del estudio de los aspectos políticos en sentido estricto $^{73}$. Manuel Morales, en su artículo sobre las fiestas marineras entre los siglos XIX y XX, describe unas manifestaciones culturales que derivan en la continua tensión manifestada entre la población externa al mundo marítimo, que intenta reapropiarse del significado de esas fiestas, el sector marinero que se siente "desposeído" por este fenómeno y las autoridades que intentan imponer otro sentido a los festejos ${ }^{74}$.

\subsection{Historia de las mujeres e historia de género}

En palabras de Gerda Lerner, las mujeres han operado como agentes de cambio en la historia, protagonizando acontecimientos y episodios, a pesar de que el relato histórico haya invisibilizado las experiencias femeninas ${ }^{75}$. La medida del mundo ha sido tradicionalmente concebida desde un sesgo patriarcal, exclusivamente masculino, restringiendo una mirada más amplia que acercase los discursos históricos construidos a las prácticas de vida, a la realidad. El cambio de paradigma que abogaba por una perspectiva que permitiera contemplarlas como sujetos históricos, fue propiciado por algunas aportaciones procedentes del ámbito marxista, en especial en la obra clave de Thompson, La formación de la clase obrera en Inglaterra, que, en 1963, inauguraba una nueva forma de analizar la historia ${ }^{76}$, pero se debió sobre todo al pensamiento y la práctica feminista. Aunque el marxismo británico y sus seguidores promovieron la construcción de una

71. R. DaRnton (1987).

72. M. ${ }^{a}$ D. Ramos Palomo (1995).

73. L. Prieto Borrego (2006).

74. M. Morales MuÑoz (2011).

75. G. LERNER (1990), 20.

76. Е. Р. Тномеsоn (1963).

(C) Baetica. Estudios Historia Moderna y Contemporánea, 39, 2019, 45-73. Facultad de Filosofia y Letras, Universidad de Málaga. Departamento de Historia Moderna y Contemporánea 
nueva historia contada desde abajo ${ }^{77}$, no fue este núcleo en el que eclosionó la historia de las mujeres.

Hacia la década de los 70 las mujeres comenzaron a escribir su pasado y lo harían en una época convulsa de luchas sociales y políticas desplegadas por el movimiento de los derechos raciales en Norteamérica, el rechazo de la guerra de Vietnam, el mayo francés del 68, la Primavera de Praga, la necesidad de conseguir la igualdad sexual o las movilizaciones por la democracia en los regímenes dictatoriales de España, Portugal y Grecia. Pero es cierto que hubo una causa que determinó de forma directa el despegue de la historia de las mujeres: la segunda ola del movimiento feminista. Los debates y reflexiones devenidos en sus filas llevaron a un grupo de historiadoras, seguidoras de los postulados de Simone de Beauvoir en El segundo sexo y de Betty Friedan en La mística de la feminidad, a buscar e introducir en la historia nuevos conceptos y enfoques metodológicos ${ }^{78}$.

Las contribuciones realizadas en un primer momento perseguían la recuperación de personajes femeninos olvidados o desdibujados en los textos históricos. No obstante, la capacidad de expansión y la pluralidad de la historia de las mujeres contribuyeron a que pronto se abordaran otras temáticas como el trabajo, la maternidad y la vida familiar, entre otras. El hecho de inscribir la historia de las mujeres en lo social implicaba pasar de soslayo sobre el protagonismo femenino en la esfera política, con la excusa de la división de espacios: públicos (masculinos) y domésticos (femeninos) ${ }^{79}$. El esfuerzo de las historiadoras para esclarecer la asimetría de los poderes políticos y la situación subordinada de las mujeres en ellos encontró en la corriente relacional de la historia un núcleo nodal.

La historia de género, hija conceptual de la historia de las mujeres, fue definida y difundida por Joan W. Scott, para quien el género es una construcción sociocultural que implica relaciones de poder en el marco de las relaciones sociales que se producen entre los $\operatorname{sexos}^{80}$. Así mismo, es un sistema de relaciones que implican significados de poder y resitúan de manera desigual y subordinada las experiencias femeninas. La historia de género, desde un enfoque amplio y transversal, resalta:

77. R. Samuel (1983).

78. M. ${ }^{a}$ D. Ramos Palomo (2015), 212-213.

79. E. Hernández Sandoica (2004), 456.

80. J. W. Sсотт (1990). 
la importancia de las interconexiones entre las diferentes relaciones sociales, entendidas como relaciones desiguales marcadas por desequilibrios de poder y por las negociaciones en torno a él, y se ha convertido en punto de confluencia y de debate de numerosas cuestiones relacionadas con la ciudadanía, el trabajo, el empleo, el salario, los movimientos sociales, el poder, la nación, las culturas políticas, la formación de la clase social, el lenguaje, la construcción de las identidades... ${ }^{81}$

La recepción de la historia de las mujeres en España se circunscribe cronológicamente a la década de los 70 en el marco de la lucha contra la dictadura y la efervescencia del movimiento feminista durante la transición. De forma temprana encontramos los trabajos pioneros de Rosa Capel, Mary Nash, Teresa Vinyoles y Amparo Moreno ${ }^{82}$, que sirvieron de acicate a posteriores investigaciones. En consonancia con la historiografía sobre la guerra civil, la historia de las mujeres tuvo también un afluente externo procedente del trabajo de algunas hispanistas como Geraldine Scanlon ${ }^{83}$ y Giuliana Di Febo ${ }^{84}$. En este sentido, a partir de los 80, a la influencia ejercida por las autoras angloamericanas se sumaba la de la escuela francesa, que introdujo en sus registros históricos el de los discursos, los imaginarios y las representaciones ${ }^{85}$ y rescató en sus temáticas la relación diferencial entre los sexos, por las historiadoras italianas ${ }^{86}$. Por otra parte, también numerosas historiadoras italianas resaltaron el derecho a la diferencia rechazando las categorías universales de "carácter neutro" 87.

La década de los noventa significó un claro avance de los estudios de las relaciones género y de la historia las mujeres en las universidades españolas, un avance visible en los debates y reflexiones teóricas, metodológicas y epistemológicas. Fruto del carácter plural, interdisciplinario, de los amplios enfoques y del herraje conceptual heredado de los estudios feministas y la historiografía europea y norteamericana, los trabajos al uso han dado como resultado en España nuevas perspectivas históricas que han contribuido a remodelar la disciplina. Junto a la producción científica, el apoyo institucional no tardó en desplegarse originando la creación de

81. M. ${ }^{\text {a }}$ D. Ramos Palomo (2015), 213-214.

82. R. Capel (1975b); M. Nash (1975), M. Amparo (1977); T. Vinyoles (1976).

83. G. SCANLON (1976).

84. G. Di Febo (1979).

85. M. Perrot (1995).

86. L. Irigaray (1978).

87. M. ${ }^{a}$ D. Ramos Palomo (2006a), 22-23. 
entidades como la Asociación Universitaria de Estudios de las Mujeres (AUDEM) y la Asociación Española de Investigación Histórica de las Mujeres (AEIHM), Institutos y Seminarios de Estudios de las Mujeres y de Género, y la publicación de revistas especializadas: Duoda (Universidad de Barcelona, 1991), Arenal (Universidad de Granada, 1993), Asparkía (Universidad Jaime I. Castellón, 1992), Anuario de Hojas de Warmi (Universidad de Barcelona, 1996) y Feminismo/s (Universidad de Alicante, 2003), entre otras. En último lugar, hay que mencionar las obras de síntesis ${ }^{88}$ que demuestran el esfuerzo intelectual realizado en estas dos décadas y las cotas de madurez alcanzadas ${ }^{89}$.

El carácter interdisciplinar y la forma ecléctica en la interrelación de los ejes temáticos posibilitados por el estudio de las relaciones de género facilitaron de forma temprana la adopción de nuevas metodologías tanto en el plano internacional como en el nacional. En los artículos de la revista Baetica hemos rastreado a modo de ejemplo esta evolución, aun cuando se trata de una publicación no especializada en esta temática. Los primeros retazos aparecieron a finales de la década de los 80 con un trabajo de María Dolores Ramos Palomo, que, en la línea apuntada por Rosa Capel, trataba la polémica desatada en torno al voto femenino y las elecciones del bienio 1931-1933 ${ }^{90}$. Sin duda, la política en su sentido tradicional ha sido uno de los ámbitos que más se ha resistido a ser investigado por la historia de las mujeres debido a la ausencia de éstas de las dinámicas de poder. La investigación de María Teresa Vera Balanza plantea la posición de las mujeres con respecto a las políticas del régimen franquista, no como sujetos sumisos y abnegados al servicio de la patria, sino más bien al contrario, resaltando la politización (falangismo, nacionalcatolicismo) explícita o no de los roles femeninos ${ }^{91}$.

No obstante, será durante la primera y la segunda década del cambio de centuria donde encontremos un mayor número de contribuciones dedicadas a esta temática. En el periodo inmediatamente anterior se incubaron avances teóricos y metodológicos que darían su fruto en las investigaciones de años posteriores. Así, María Dolores Ramos y María Teresa Vera revisaron conjuntamente en un artículo los cambios introducidos en la historia de las

88. B. S. Andersson y J. P. Zinsser (1992); G. Duby y M. Perrot (1993); E. Garrido (1997); J. Cuesta Bustillo (2003); I. Morant (2003).

89. M. ${ }^{a}$ D. Ramos Palomo (2006a), 25-28.

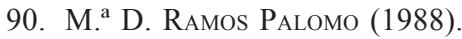

91. M. ${ }^{a}$ T. Vera Balanza (1992). 
mujeres utilizando como ejes de su aportación el trabajo, la ciudadanía y las formas de conciencia ${ }^{92}$. Esta retrospectiva se asociaba a un trasfondo en el que la consolidación de la madurez de la historia de las mujeres y la historia de género era visible en las universidades españolas. Las sucesivas contribuciones publicadas son el mejor indicador de este hecho.

El trabajo de Lucía Prieto acerca de las experiencias femeninas en el éxodo republicano tiene la peculiaridad de utilizar fuentes orales entre la documentación primaria ${ }^{93}$. La historia oral ha tenido un especial significado en la historia de las mujeres al servir como registro de las voces y las experiencias femeninas ausentes en los documentos escritos. Durante el franquismo, el ideal de feminidad enclaustró a las mujeres en la esfera doméstica invisibilizando su presencia en la historia bajo el tupido telón de lo cotidiano. En este sentido, los estudios de Carmen Romo ${ }^{94}$ y María Remedios García ${ }^{95}$ redundan en la historia de la vida cotidiana reflejando el papel de las amas de casa durante el mismo periodo. El objetivo enunciado era recuperar la historia de las mujeres, quienes, a pesar de haber estado subordinadas social y políticamente, protagonizaron, como apuntan estos trabajos, numerosas experiencias (trabajos domésticos, trabajos a domicilio, tareas de reproducción biológica y social, labores de cuidado) imprescindibles no sólo para la vida doméstica sino para la nación.

Retomando la relación de las mujeres con lo político, María Dolores Ramos investiga el papel que juegan las leyes y el movimiento de mujeres en la construcción de la ciudadanía y la relación entre el Estado-nación y lo femenino ${ }^{96}$. Por su parte, María José González Castillejo cruza las categorías analíticas clase, género y cultura política en su acercamiento a la construcción identitaria de las mujeres trabajadoras durante la dictadura de Primo de Rivera ${ }^{97}$.

En fin, a modo de cierre de este repaso historiográfico, es menester resaltar las contribuciones dedicadas a la biografía o que contienen aspectos biográficos, en un ejercicio que supone volver a un eje temático que resonaba ya en las primeras manifestaciones de la historia de las mujeres. La biografía es un género que se ha renovado completamente al hilo de la

92. M. ${ }^{\text {a }}$ D. Ramos Palomo y M. ${ }^{\text {a }}$ T. Vera Balanza (2001).

93. L. Prieto Borrego (2002).

94. C. Romo Parra (2007).

95. M. ${ }^{a}$ R. García Muñoz (2012).

96. M. ${ }^{\text {a }}$ D. Ramos Palomo (2012).

97. M. ${ }^{a}$ J. González Castillejo (2009). 
aplicación de una novedosa metodología ${ }^{98}$, en parte gracias a los estudios socioculturales, de género, y a las influencias de la microhistoria. Se trata de examinar el objeto de estudio, excepcional o no, como un caso que contribuye a visualizar en sí mismo el contexto histórico que lo rodea y su relación con el plano estructural, ya sea desde una perspectiva individual o desde un enfoque colectivo. Destacan, en este sentido, el estudio del republicano Pedro Armasa Ochandorena por Fernando Arcas Cubero ${ }^{99}$, la republicana, librepensadora y feminista Belén Sárraga realizado por María Dolores Ramos Palomo ${ }^{100}$, y la aportación de María José González Castillejo sobre la matrona malagueña Josefa Lázaro en los años $20^{101}$.

Si hemos señalado que la historia de las mujeres y la historia de género albergan una gran riqueza teórica y metodológica impulsada sin duda por su carácter interdisciplinar y por los avances historiográficos de las últimas décadas del siglo XX, esa riqueza, cada vez más plural, se ha incrementado en el nuevo milenio, como se refleja en numerosos debates y reflexiones.

\section{BALANCE Y NUEVOS RETOS}

La revista Baetica ha sabido recoger a lo largo de 40 años de existencia, las renovaciones metodológicas, conceptuales, epistemológicas y temáticas que se han ido produciendo en la historiografía tanto a nivel nacional como internacional. Igual que otras revistas departamentales creadas en los primeros años de la democracia, Baetica es un claro ejemplo de los esfuerzos realizados tanto por las universidades como por el profesorado para construir una plataforma en la que se materializaran los cambios historiográficos y las investigaciones realizadas o en curso. Como hemos visto, la presencia de lo local ha tenido un amplio protagonismo a la hora de inscribir lo micro en estructuras nacionales de mayor calado cristalizando en una dinámica de relaciones y conexiones entre ambos polos. Así mismo, desde otra vertiente, esta forma de construir e interpretar la historia ha posibilitado las búsquedas documentales en los archivos locales y la incorporación de nuevas fuentes y metodologías.

En el año 2018, la revista cerraba una larga etapa abriendo a su vez una segunda época con un cambio de denominación que, lejos de lo me-

98 H. Gallego y M. Bolufer (2016).

99 F. Arcas Cubero (1985).

100 M. ${ }^{a}$ D. Ramos Palomo (2006b).

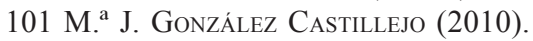


ramente nominal, iba a repercutir en las circunscripciones disciplinares y cronológicas. Baetica. Estudios de Historia Moderna y Contemporánea recoge el legado precedente a la vez que aborda las diversas temáticas que alumbran las vanguardias historiográficas producidas en el presente, lo que supone afrontar retos diferentes. En la última década una de las ramas que ha concitado gran interés ha sido la historia de las emociones ${ }^{102}$, que, en el terreno de lo sociocultural, ha sabido aglutinar diversos enfoques y su carácter interdisciplinar en las formas de interrelacionarse con una gran diversidad de manifestaciones culturales y políticas ${ }^{103}$. La facilidad para cruzar otras ramas y disciplinas ha hecho que las emociones sean investigadas desde la historia de género y la historia de las mujeres ${ }^{104}$. Como apuntábamos anteriormente, la primera ha evolucionado hasta posicionarse historiográficamente en la vanguardia mostrando una profundización hacia lo cultural, no solo desde las emociones sino también en referencia a la construcción de las identidades ${ }^{105}$. La importancia del bagaje subjetivo en los cambios identitarios ha suscitado la atención en diversos estudios debido a la complejidad que guardan este tipo de procesos. Así mismo, la conexión existente entre la nación y las relaciones de género y el acercamiento hacia lo cultural han servido de estímulo para la realización de nuevas investigaciones ${ }^{106}$.

La historia política no puede negar las influencias de lo sociocultural, de la historia de género y de la historia de las emociones, como si de un organismo vivo se tratase. Más allá de los compartimentos estancos, lo que resalta más bien es una conexión interdisciplinar ineludible. En este sentido, el estudio de las violencias o las vinculaciones realizadas entre el nacionalismo y las identidades han mostrado resultados muy interesantes ${ }^{107}$. En fin, en el marco de la historia del tiempo presente, las investigaciones ligadas a las industrias culturales ocupan un importante lugar. En la era digital que transitamos actualmente hemos sido testigos de la irrupción de nuevos productos mediáticos entre los que citamos como botón de muestra las series televisivas, que viven en nuestros días su segunda época dorada, y la industria de los videojuegos. Ambas han

102. J. J. Díaz Freire (2015); J. Plamper (2014); P. Burke (2005).

103. L. E. Delgado, P. Fernández y J. Labanyi (2018); S. Ahmed (2004); G. Bruno (2002).

104. R. M. Medina Domenech (2012); M. Naussbaum (2013).

105. Á. Cenarro (2017).

106. N. Aresti, K. Peters y J. Brühne (2016); I. Blasco Herranz (2018); M. García FerNÁNDEZ (2017).

107. E. González Calleja (2008); J. Moreno Luzón y X. Núñez Xeixas (2013). 
dinamizado el consumo de ocio capitalista reestructurando el espacio y el tiempo así como la forma en que nos relacionamos con ellos. Estas mutaciones, que afectan sobre todo a segmentos concretos de la población relacionados con las categorías de edad, género y clase, han sido trabajados desde la historia sociocultural ${ }^{108}$.

En definitiva, la historiografía española ha sabido reconocer los préstamos conceptuales y metodológicos de otras disciplinas asistiendo a la eclosión de una diversidad temática, de nuevas especialidades, y a un cada vez más acusado cruce interdisciplinar. A día de hoy, la historia goza de buena salud, de amplias miras y de un eclecticismo articulado en diferentes relatos. La revista Baetica, en su segunda época y de acuerdo con su trayectoria anterior, sabrá plasmar esta pluralidad de planteamientos en sus páginas, promoviendo el interés de numerosos historiadores e historiadoras.

\section{BIBLIOGRAFÍA}

Aguado, Ana y Ramos Palomo, María Dolores (2002), La modernización en España (1917-1939). Cultura y vida cotidiana, Síntesis, Madrid.

Aguilar, Paloma (1995), La memoria histórica de la guerra civil española (19361939): un proceso de aprendizaje político, Instituto Juan March, Madrid Ahmed, Sara (2004), The cultural politics of emotion, Routledge, Nueva York.

Alted Vigil, Alicia (1991), "Las mujeres en la sociedad española de los años cuarenta", en Las mujeres y la guerra civil española. III Jornadas de Estudios Monográficos, Ministerio de Trabajo e Inmigración, Instituto de la Mujer, Madrid, pp. 293-303.

Anderson, Bonnie S. y Zinsser, Judith P. (1992), Historia de las mujeres: una historia propia, Crítica, Barcelona.

ArCas CUBero, Fernando (1980), El movimiento georgista y los orígenes del andalucismo. Análisis del periódico "El Impuesto único", Confederación Española de Cajas de Ahorro, Madrid.

- (1985), "Pedro Armasa Ochandorena (1864-1933). Trayectoria política de un republicano", Baetica. Estudios de Arte, Geografía e Historia, 8, pp. 423=434.

- (1989), "Málaga en el 98. Repercusiones sociales de la guerrahispano-cubanonorteamericana", Baetica. Estudios de Arte, Geografia e Historia, 12, pp. 279-298.

Arco Blanco, Miguel Ángel del (2007), Hambre de siglos: Mundo rural y apoyos sociales del primer franquismo en Andalucía Oriental (1936-1951), Comares, Granada.

108. J. Labanyi (2018); F. Peñate Domínguez (2017). 
Aresti, Nerea; Peters, Karin y Brühne, Julia (coords.) (2016), ¿La España invertebrada?: masculinidad y nación a comienzos del siglo XX, Comares, Granada.

Aróstegui, Julio (1985), Historia de la guerra civil, Cuadernos de Historia 16.

- (coord.) (1988), Historia y memoria de la guerra civil, vol. I, Junta de Castilla y León, Valladolid.

- (1992), "La historiografía sobre la España de Franco. Promesas y debilidades", Historia Contemporánea, 7, pp. 77-99.

- (1995), La investigación histórica: teoría y método, Crítica, Barcelona.

BARRANQUero TeXeIRA, Encarnación (1988), "Las instituciones en la implantación del nuevo Estado: el Ayuntamiento de Málaga en 1937”, Baetica. Estudios de Arte, Geografía e Historia, 11, pp. 513-522.

- (1997), "Negociación colectiva y conflictividad social en el sector textil: Málaga 1960-1970", Baetica. Estudios de Arte, Geografia e Historia, 19 (II), pp. 233-241.

- (1998), "Cayetano Bolívar: apuntes biográficos", Baetica. Estudios de Arte, Geografia e Historia, 20, pp. 427-436.

Barranquero Texeira, Encarnación y Prieto Borrego, Lucía (2003), Así sobrevivimos al hambre: estrategias de supervivencia de las mujeres en la posguerra española, Diputación, Málaga.

Blanco Rodríguez, Juan Andrés (2007), "La historiografía de la guerra civil española”, Hispania Nova, 7, pp. 741-774.

Blasco Herranz, Inmaculada (1999), Armas femeninas para la contrarrevolución: la sección femenina en Aragón, (1936-1950), Universidad, Málaga.

- (2018), “¿Qué mujeres para qué España?: feminidad y nación en el feminismo español (1900-1923)", en H. Gallego Franco (ed.), Feminidades y masculinidades en la historiografía de género, Comares, Granada, pp. 105-126.

Broué, Pierre y tÉmime, Emile (1977), Guerra y revolución en España, Fondo de Cultura Económica, México.

Bruno, Giuliana (2002), Atlas of emotion: journeys in art, arquitecture and film, Verso, Nueva York.

Burke, Peter (2005), "Is there a cultural history of the emotions?", en P. Gouk Y H. Hills (eds.), Representing emotions: New connections in the history of art, music and medicine, Ashgate, Aldershot, pp. 35-47.

Cabrera Acosta, Miguel Ángel (2001), "Historia y teoría de la sociedad: del giro culturalista al giro lingüístico”, en C. ForCAdell e I. Peiró (coords.), Lecturas de la historia. Nueve reflexiones sobre Historia de la Historiografía, Institución Fernando el Católico, Zaragoza.

Capel Martínez, María Rosa (1975), "Los partidos políticos ante el voto femenino en la segunda república española”, Anuario de Estudios Sociales y Jurídicos, 4, pp. 299-328.

CARR, Raymond (1977), The spanish tragedy: the Civil War in perspective, Weidenfeld, Londres. 
Carreras Ares, Juan José (1981), “El marco internacional de la Segunda República", Arbor, 109, 426, pp. 37-50.

Casanova, Julián (1992), La historia social y los historiadores: ¿Cenicienta o princesa?, Crítica, Barcelona.

- (1999), El pasado oculto. Fascismo y violencia en Aragón (1936-1939), Mira Editores, Zaragoza.

- (2008), "Pasado y presente de la guerra civil española", Historia social, 60, pp. 113-128.

Cipolla, Carlo M. (1991), Entre la historia y la economía. Introducción a la historia económica, Crítica, Barcelona.

Cenarro, Ángela (1995), Los orígenes y la naturaleza del franquismo en Aragón (1936-1945), Tesis doctoral, Universidad de Zaragoza.

- (2017), "La Falange es un modo de ser (mujer): discursos e identidades de género en las publicaciones de la Sección Femenina (1938-1945)", Historia y Política. Ideas, Procesos y Movimientos Sociales, 37, pp. 91-120.

Cerón Torreblanca, Cristian (2007), “De la guerra de los abuelos, a la guerra de las esquelas: 70 años del aniversario de la guerra civil española y del comienzo del Franquismo", Baetica. Estudios de Arte, Geografía e Historia, 29, pp. 473-484.

- (2008), "El partido único durante el franquismo. FET y de las JONS en Málaga", Baetica. Estudios de Arte, Geografía e Historia, 30, pp. 403-414.

- (2010), "La prevención de riesgos laborales y el mundo del trabajo durante la dictadura franquista", Baetica. Estudios de Arte, Geografía e Historia, 32, pp. 493-505.

Cuesta Bustillo, Josefina (dir.) (2003), Historia de las mujeres en España. Siglo XX, 4 vols., Instituto de la Mujer, Madrid.

DARNTON, Robert (1987), La gran matanza de gatos y otros episodios en la historia de la cultura francesa, Fondo de Cultura Económica, México.

Delgado, Luisa Elena; Fernández, Pura y Labanyi, Jo (eds.) (2018), La cultura de las emociones y las emociones en la cultura española contemporánea (siglos XVIII-XXI), Cátedra, Madrid.

Díaz Freire, José Javier (ed.) (2015), "Emociones e historia”, dossier en Ayer, 98 (2).

Dios Fernández, Eider de (2016), Clase, Género e Identidad a través del Servicio Doméstico en el Gran Bilbao durante el franquismo, Tesis doctoral, Universidad del País Vasco.

Domínguez, Pilar (1994), Voces del exilio: mujeres españolas en México (19391950), Dirección General de la Mujer, Madrid.

Duby, Georges y Perrot, Michelle (1993), Historia de las mujeres en Occidente, 5 vols., Taurus, Madrid.

Eley, Geoff, (2008), Una línea torcida: de la historia cultural a la historia de la sociedad, Universidad, Valencia.

Espadas Burgos, Manuel (1987), Franquismo y política exterior, Rialp, Madrid. 
Baetica, 40 años de Historia Contemporánea. Investigaciones, tendencias...

Espinosa Mestre, Francisco (2005), El fenómeno revisionista o los fantasmas de la derecha española, Del Oeste Ediciones, Badajoz

Febo, Giuliana di (1979), Resistencia y movimiento de mujeres en España, 1936 1976, Icaria, Barcelona.

Fernández Paradas, Mercedes (2006), "La casa Carreira: un ejemplo de la pequeña empresa de electricidad en Andalucía (1903-1935)", Baetica. Estudios de Arte, Geografía e Historia, 28, pp. 583-600.

- (2010), "Los comienzos de la electricidad en Andalucía: el ejemplo de Antequera (1892-1912)", Baetica. Estudios de Arte, Geografía e Historia, 32, pp. 507-525.

Fogel, Robert (1994), "El crecimiento económico, la teoría de la población y la fisiología: la influencia de los procesos a largo plazo en la elaboración de la política económica", Revista de Historia Económica, 12 (3), pp. 719-762.

Fontana, Josep (ed.) (1986), España bajo el franquismo, Crítica, Barcelona.

Fraser, Ronald (1979), Recuérdalo tú y recuérdalo a otros. Historia oral de la guerra civil española, Crítica, Barcelona.

Gallego Méndez, María Teresa (1983), Mujer, falange y franquismo, Taurus, Madrid.

Gallego Franco, Henar y Bolufer, Mónica (eds.) (2016), ¿Y ahora qué? Nuevos usos del género biográfico, Icaria, Barcelona.

García Fernández, Mónica (2017), “Sexualidad y armonía conyugal en la España franquista. Representaciones de género en manuales sexuales y conyugales publicados entre 1946 y 1968", Ayer, 105, pp. 215-238.

García Montoro, Cristóbal (1978), “Málaga en 1862: la exposición provincial de productos", Baetica. Estudios de Arte, Geografía e Historia, 1, pp. 417-427.

- (1979), "Notas sobre el proteccionismo de los industriales malagueños del siglo XIX”, Baetica. Estudios de Arte, Geografia e Historia, 2 (II), pp. 327-343.

- (1980), "Antimaquinismo en Antequera a mediados del siglo XIX: los sucesos del verano de 1854", Baetica. Estudios de Arte, Geografía e Historia, 3, pp. $265-288$.

García Muñoz, María Remedios (2012), "Memoria y vida cotidiana. Las amas de casa de Almogía durante el franquismo", Baetica. Estudios de Arte, Geografia e Historia, 34, pp. 451-471.

GArrido, Elisa (ed.) (1997), Historia de las mujeres en España, Síntesis, Madrid. GonZÁlez, Manuel Jesús (1979), La economía política del franquismo (1940-1970), Tecnos, Madrid.

GonzÁlez Calleja, Eduardo (2008), "La violencia política en la España del siglo XX: un balance historiográfico", Mélanges de la Casa de Velázquez, 38 (2), pp. 213-240.

González Castillejo, María José (1999), “La publicidad económica, un instrumento político contra la lucha de clases en la dictadura de Primo de Rivera (1923-1930)", Baetica. Estudios de Arte, Geografía e Historia, 21, pp. 401-419. 
- (2009), "Sobre identidad y rebeldía: la construcción del género y la clase en la dictadura de Primo de Rivera", Baetica. Estudios de Arte, Geografía e Historia, 31, pp. 513-524.

- (2010), "Josefa Lázaro o la conciencia de ser matrona en la Málaga de los años 20", Baetica. Estudios de Arte, Geografía e Historia, 32, pp. 527-538.

HernÁNDEZ SANDOICA, Elena (2004), Tendencias historiográficas actuales. Escribir historia hoy, Akal, Madrid.

- (2005), Sobre la Historia actual. Entre política y cultura, Abada, Madrid.

Irigaray, Luce (1978), Speculum. Espéculo de la otra mujer, Saltés, Madrid.

JACKSON, Gabriel (1976), La república española y la guerra civil, Crítica, Barcelona.

Jover zamora, José María (1976), Política, diplomacia y humanismo popular. Estudios sobre la vida española del siglo XIX, Turner, Madrid.

LABANYI, Jo (2018), "Competencia emocional y discursos del sufrimiento en la serie televisiva Amar en tiempo revueltos", en L. E. Delgado; P. Fernández y J. LABANYi, (eds.), La cultura de las emociones y las emociones en la cultura española contemporánea (siglos XVIII-XXI), Cátedra, Madrid, pp. 273-292.

Lacomba Abellán, José Antonio (1995), "Sobre historia local y microhistoria. Una aproximación”, Isla de Arriarán, 6, pp. 129-136.

Lerner, Gerda (1990), La creación del patriarcado, Crítica, Barcelona.

Llona, Miren (2002), Entre señorita y garçonne. Historia oral de las mujeres bilbainas de clase media (1919-1939), Colección Atenea, Universidad, Málaga.

Losada Álvarez, Juan Carlos (1990), Ideología del Ejército Franquista. 19391959, Istmo, Madrid.

Maravall, José María (1978), Dictadura y disentimiento político. Obreros y estudiantes bajo el franquismo, Alfaguara, Madrid.

Marín Gelabert, Miquel (2001), "Historiadores locales e historiadores universitarios. La historiografía española en su contexto internacional, 1948-1965", en C. Forcadell e I. Peiró (coords.), Lecturas de la historia. Nuevas reflexiones sobre la historia de la historiografía, Institución Fernando el Católico, Zaragoza, pp. 97-150.

Medina Domenech, Rosa María (2012), "Sentir la historia. Propuestas para una agenda de investigación feminista en la historia de las emociones", Arenal. Revista de Historia de las Mujeres, 19 (1), pp. 161-199.

Moradiellos, Enrique (2001), El reñidero de Europa: las dimensiones internacionales de la Guerra Civil Española, Península, Barcelona.

- (2007), "Revisión histórica crítica y revisionismo político presentista: el caso español”, en J. Cuesta (dir.), Memorias históricas de España (siglo XX), Fundación Francisco Largo Caballero, Madrid, pp. 372-388.

Morales MuÑoz, Manuel (1982), “Aproximación al estudio de la conflictividad social en Málaga: 1868-1874”, Baetica. Estudios de Arte, Geografía e Historia, 5, pp. 355-360.

- (1983), "La lucha política en Málaga durante el «sexenio revolucionario»", Baetica. Estudios de Arte, Geografía e Historia, 6, pp. 341-386. 
- (1991), "En los orígenes del anarquismo agrario: el campesinado malagueño y la «Federación Regional Española» de la AIT", Baetica. Estudios de Arte, Geografía e Historia, 13, pp. 281-294.

- (1992), "Historia de un conflicto social: Málaga, la huelga general del verano de 1872", Baetica. Estudios de Arte, Geografía e Historia, 14, pp. 327-339.

- (1999), "El papel de las élites en la industrialización andaluza", Baetica. Estudios de Arte, Geografía e Historia, 21, pp. 431-449.

- (2008), "Entre el cielo y la tierra. La represión franquista en Málaga", Baetica. Estudios de Arte, Geografia e Historia, 30, pp. 431-445.

- (2011), "Las fiestas marineras en los siglos XIX y XX: entre la afirmación identitaria y la «desposesión»", Baetica. Estudios de Arte, Geografía e Historia, 33, pp. 443-458.

Morales Muñoz, Manuel y Ortega Berenguer, Emilio (2001), “El asociacionismo empresarial en Andalucía (1868-1923): entre la defensa de los intereses de clase y la resistencia al cambio social”, Baetica. Estudios de Arte, Geografía e Historia, 23, pp. 675-691.

Morant, Isabel (dir.), Historia de las mujeres en España y América Latina, 4 vols., Cátedra, Madrid.

Moreno Luzón, Javier y NúÑez XeIXAs, Xoxé (2013), Ser españoles: imaginarios nacionalistas en el siglo XX, RBA, Madrid.

Moreno Seco, Mónica (2012), "Mujeres en la Acción Católica y el Opus Dei. Identidades de género y culturas políticas en el catolicismo de los años sesenta", Historia y Política. Ideas, Procesos y Movimientos Sociales, 28, pp. 167-194.

Muñoz Ruiz, María del Carmen (2002), Mujer mítica, mujeres reales: las revistas femeninas en España, 1955-1970, Tesis doctoral, Universidad Complutense de Madrid.

Nadal Sánchez, Antonio (1978), "Fondos bibliográficos y documentales para el estudio de la Guerra Civil en Málaga, 1936-1937”, Baetica. Estudios de Arte, Geografía e Historia, 1, pp. 429-435.

— (1983), "Acontecimientos militares en Málaga (Julio del 36 a febrero de 1937)", Baetica. Estudios de Arte, Geografía e Historia, 6, pp. 387-411.

- (2006), "Comité de Salud Pública", Baetica. Estudios de Arte, Geografía e Historia, 28, pp. 627-648.

NAsh, Mary (1981), Mujer y movimiento obrero en España (1931-1939), Fontamara, Barcelona.

- (2006), Rojas. Las mujeres republicanas en la guerra civil, Taurus, Madrid.

North, Douglass Cecil (1971), The Rise of the Western World: A New Economic History, University Press, Cambridge.

Nussbaum, Martha C. (2013), Political emotions: why love matters for justice, Cambridge, University Press, Harvard.

Ortega Berenguer, Emilio (1978), "Situación de la enseñanza en Málaga antes del 14 de abril de 1931", Baetica. Estudios de Arte, Geografía e Historia, 1, pp. 437-453. 
- (1985), “La enseñanza en Andalucía contemporánea: la primera enseñanza entre 1840-1850 y Pascual Madoz", Baetica. Estudios de Arte, Geografía e Historia, 8, pp. 489-514.

Parejo Barranco, José Antonio (1980), "La crisis de subsistencias de 1868 en Antequera”, Baetica. Estudios de Arte, Geografía e Historia, 3, pp. 289-302.

PAYNe, Stanley (1976), La revolución y la guerra civil española, Madrid, Júcar.

Peñate Domínguez, Federico (2017), "Los historical game studies como línea de investigación emergente en las Humanidades", Cuadernos de Historia Contemporánea, 39, pp. 387-398.

Perrot, Michelle (1995), "Escribir la Historia de las mujeres. Una experiencia francesa", Ayer, 17, pp. 67-83.

Plamper, Jan (2014), "Historia de las emociones", Cuadernos de Historia Contemporánea, 36, pp. 17-29.

Polanyi, Karl (2018), Economy and society: selected writings, Polity Press, United Kingdom.

Preston, Paul (2011), La guerra civil española. Reacción, revolución y venganza, Debate, Madrid.

Prieto Borrego, Lucía (2000), “«El terror rojo» en la Causa General de Casares”, Baetica. Estudios de Arte, Geografía e Historia, 22, pp. 525-545.

- (2001), "La situación de las clases trabajadoras en Marbella durante las primeras décadas del siglo XX", Baetica. Estudios de Arte, Geografía e Historia, 23, pp. 693-712.

- (2002), "Vivencias y experiencias de las mujeres en el éxodo republicano", Baetica. Estudios de Arte, Geografía e Historia, 24, pp. 515-540.

- (2003), "La violencia anticlerical en las comarcas de Marbella y Ronda durante la guerra civil", Baetica. Estudios de Arte, Geografía e Historia, 25, pp.751-772.

- (2004), "Los poderes locales de Istán y Estepona y la justicia popular (19361937)”, Baetica. Estudios de Arte, Geografía e Historia, 26, pp. 407-426.

- (2006), "La prostitución en Andalucía durante el primer franquismo", Baetica. Estudios de Arte, Geografía e Historia, 28, 665-687.

Raguer, Hilari (1977), La espada y la cruz, Bruguera, Barcelona.

Ramos Palomo, María Dolores (1980), "Conflictividad social en la coyuntura de la Primera Guerra Mundial: la huelga de Altos Hornos de Málaga (1916)", Baetica. Estudios de Arte, Geografía e Historia, 3, pp. 303-315.

- (1983), "Crisis de subsistencias y conflictividad social en Málaga: los sucesos de enero de 1918”, Baetica. Estudios de Arte, Geografía e Historia, 6, pp. 441-466.

- (1985), "Estructura social en Málaga (I). El vértice del poder, 1900-1920", Baetica. Estudios de Arte, Geografía e Historia, 8, pp. 515-534.

- (1986), "Estructura social en Málaga (II). Medianas y pequeñas burguesías. Los sectores populares, 1914-1923", Baetica. Estudios de Arte, Geografía e Historia, 9, pp. 413-430. 
— (1987), "Poder, oligarquías y somatenes en Málaga, 1919-1930”, Baetica. Estudios de Arte, Geografía e Historia, 10, pp. 385-410.

- (1988), "Luces y sombras en torno a una polémica: la concesión del voto femenino en España (1931-1933)", Baetica. Estudios de Arte, Geografía e Historia, 11, pp. 563-573.

- (1993), "La historia social contemporánea en España (1975-1989) (Cenicienta y princesa)", Baetica. Estudios de Arte, Geografía e Historia, 15, pp. 397-406.

- (1994), “El sueño eterno. Del Plan Málaga al Parque Tecnológico, 1962-1992”, Baetica. Estudios de Arte, Geografía e Historia, 16, pp. 429-440.

- (1995), “'Todos a una?: el familismo en las economías campesinas”, Baetica. Estudios de Arte, Geografia e Historia, 17, pp. 497-510.

- (1998), "Memorias de la guerra civil española y el exilio. El lenguaje de los perdedores", Baetica. Estudios de Arte, Geografía e Historia, 19 (II), pp. 283-292.

- (2006a), "Arquitectura del conocimiento, historia de las mujeres, historia contemporánea. Una mirada española. 1990-2005”, Cuadernos de Historia Contemporánea, 28, pp. 17-40.

— (2006b), "Belén de Sárraga: una «obrera» del laicismo, el feminismo y el panamericanismo en el mundo ibérico", Baetica. Estudios de Arte, Geografía e Historia, 28, pp. 689-708.

- (2012), "Estado, ciudadanía y feminismos: aproximaciones teóricas e historiográficas", Baetica. Estudios de Arte, Geografía e Historia, 34, pp. 529-550.

- (2015), "Historia de las mujeres y género. Una mirada a la época contemporánea", Historiografía, 22, pp. 211-233.

Ramos Palomo, María Dolores y Vera Balanza, María Teresa (2001), "Revisando el canon desde la historia de las mujeres: trabajo, ciudadanía y formas de conciencia", Baetica. Estudios de Arte, Geografia e Historia, 23, pp. 713-740.

Reig Tapia, Alberto (2006), Anti-Moa, Ediciones B, Barcelona.

Rodríguez López, Sofía (2008), "Los secretos de la memoria. Guerra Civil, Franquismo y Fuentes Orales en Almería", Pasado y Memoria, 7, pp. 263-283.

Romeu Alfaro, Fernanda (1987), La agrupación guerrillera de Levante, Edicions Alfons el Magnánim, Valencia.

Romo PARra, Carmen (1996), "Instrucciones para dar cuerda al reloj: planificación económica y factores de socialización en la España del Desarrollo”, Baetica. Estudios de Arte, Geografía e Historia, 18, pp. 471-486.

- (2005), "Entre el látigo y la golosina. Reflexiones sobre la construcción de la disciplina temporal contemporánea en la esfera del trabajo remunerado", Baetica. Estudios de Arte, Geografía e Historia, 27, pp. 523-541.

- (2007), "Reinas de una sociedad dentro de otra sociedad. Apuntes sobre las percepciones y sentimientos de las amas de casa en la última década del franquismo", Baetica. Estudios de Arte, Geografia e Historia, 29, pp. 499-517.

RorTy, Richard (1990), El giro lingüístico, Paidós-UAB, Barcelona.

SAMUEL, Raphael (ed.) (1983), Historia popular y teoría socialista, Crítica, Barcelona. 
SAntos, Juliá (1984), De la fiesta popular a la lucha de clases, Siglo XXI de España, Madrid.

SCANLON, Geraldine (1976), La polémica feminista en la España contemporánea (1868-1974), Siglo XXI, Madrid.

ScotT, Joan W. (1990) "El género: una categoría útil para el análisis histórico”, en J. Amelang y M. Nash (eds.): Historia y género. Las mujeres en la Europa Moderna y Contemporánea, Institució Alfons el Magnánim, Valencia, pp. 23-58.

Serna, Justo y Pons, Anacleto (1993), "El ojo de la aguja. ¿De qué hablamos cuando hablamos de microhistoria?, Ayer, 12, pp. 93-133.

Silva, Emilio y Macías, Santiago (2003), Las fosas de Franco: los republicanos que el dictador dejó en las cunetas, Temas de Hoy, Madrid.

Sobrequés i Callico, Jaume; Molinero, Carme y SAla, Margarida (coords.) (2003), Una inmensa prisión: los campos de concentración y las prisiones durante la Guerra Civil y el franquismo, Crítica, Barcelona.

SpIEgel, Gabrielle M., "La historia de la práctica: nuevas tendencias en historia tras el giro lingüístico", Ayer, 62 (2), pp. 19-50.

Thomas, Hugh (1977), The Spanish Civil War, Harper \& Row, Harper Nueva York, 1977.

Thompson, Edward Palmer (1963), La formación de la clase obrera en Inglaterra, Crítica, Barcelona.

TuÑón DE LARA, Manuel (1978a), Luchas obreras y campesinas en la Andalucía del siglo XX. Jaén (1917-1920), Sevilla (1930-1932), Siglo XXI, Madrid.

- (1978b), La España del siglo XX, Laia, Barcelona.

- (1980), Historiografía española contemporánea. X Coloquio del Centro de Investigaciones Hispánicas de la Universidad de Pau. Balance y resumen, Siglo XXI, Madrid.

- (1985), Tres claves de la II República: la cuestión agraria, los aparatos del Estado y el Frente Popular, Alianza, Madrid.

Tuñón de lara, Manuel; Aróstegui, Julio; Viñas Mey, Ángel; Cardona, Gabriel y Ricall, Josep M., (1985), La guerra civil española, 50 años después, Labor, Barcelona.

Tusell, Javier (1975), La España del siglo XX, Taurus, Madrid.

- (1977), La oposición democrática al franquismo, Planeta, Barcelona.

- (1982), Las Constituyentes de 1931: unas elecciones de transición, Centro de Investigaciones Sociológicas, Madrid.

Velasco Gómez, José (1982), “La conflictividad campesina en Antequera durante el bienio social-azañista (1931-1933)", Baetica. Estudios de Arte, Geografía e Historia, 5, pp. 409-426.

- (1983), "Las elecciones del Frente Popular en Málaga, 1936”, Baetica. Estudios de Arte, Geografía e Historia, 6, pp. 467-493.

Vera Balanza, María Teresa (1992), "Literatura femenina y mentalidad religiosa en el franquismo", Baetica. Estudios de Arte, Geografia e Historia, 14, pp. 361-376. 
Baetica, 40 años de Historia Contemporánea. Investigaciones, tendencias...

Viñas Mey, Ángel (1979), El oro de Moscú. Alfa y omega de un mito franquista, Grijalbo, Barcelona.

- (1984), Guerra, dinero, dictadura. Ayuda fascista y autarquía en la España de Franco, Crítica, Barcelona.

- (2006), La soledad de la República: el abandono de las democracias y el viraje hacia la Unión Soviética, Crítica, Barcelona. 